\title{
Effect of Solidification Parameters on the Feeding Efficiency of Lm6 Aluminium Alloy Casting
}

\author{
V. Gopinath ${ }^{1}$, N. Balanarasimman ${ }^{2}$ \\ ${ }^{I}$ (Mechanical Engineering, Kongunadu College of Engineering and Technology/ Anna University, India) \\ ${ }^{2}$ (Mechanical Engineering, Mahendra Engineering College/ Anna University, India)
}

\begin{abstract}
Now a days, significant amount of aluminium alloy are being used to fabricate components such as engine blocks, cylinder heads, suspension control arms, wheels and pistons. In response to consumer demands for the increase in performance, the use of aluminium has grown dramatically in the recent years. So in order to produce a sound LM6 (Al-12\%Si) Aluminium alloy casting, a new approach is made in this work. Plate casting of dimension 240x150x25 mm is employed with the combination of different riser dimensions. Cylindrical riser of hemispherical bottom with $H / D=1$ are taken for this analysis. Solidification simulation is made with ANSYS software, then the solidification time and optimal riser diameters are compared with experimental results.
\end{abstract}

Keywords - Aluminium alloy casting, Feeder Design, Solidification simulation

\subsection{Introduction}

\section{INTRODUCTION}

Metal casting is one of the most ancient techniques used for manufacturing metal parts. Metal casting is the process of producing metal component parts of desired shapes by pouring the molten metal into the prepared mould (of that shape) and then allowing the metal to cool and solidify. Casting is one of the fundamental types of manufacturing any type of products. In response to consumer demands for increased performance and fuel economy, the use of aluminium in the automotive industry has grown dramatically in recent years. Today, significant amount of aluminium alloy are being used to fabricate components such as engine blocks, cylinder heads, suspension control arms, front strut suppliers, wheels and pistons. The volume of the cast aluminium components is projected to grow significantly. So in order to produce a sound aluminium casting in the economical manner, a new approach in the riser design is needed.

\subsection{Process Description}

The process of casting involves the basic operations of pattern making, sand preparation molding, melting of metal pouring of moulds, cooling, shake-out, fettling, heat treatment, finishing and inspection. In casting process, the solidification of liquid metal in the mould cavity plays a major role. Such a phase change from liquid to solid state involves the phenomena like changes in fluidity, volumetric shrinkage, segregation, evolving of gases absorbed and the size of the grains which have profound influence on the quality of the final casting obtained. A proper understanding of solidification mechanism helps in avoiding major casting defects.

\subsection{Moulding of Aluminium Casting}

\section{ALUMINIUM ALLOY FOUNDRY PRACTICE}

Aluminium alloys can be cast by any of the commonly used processes; sand casting, plaster moulding, permanent mould, and die-casting. Because of the low pouring temperature and specific gravity of aluminium alloys, moulds are less affected by heat less than in case of iron and steel. Consequently excellent surface finish can be obtained even in large sand castings.

\subsection{Sand Casting}

Casting in moulds made by any of the usual sand-moulding processes is practiced with aluminium alloys. Green-sand moulding with conventional moulding equipment is used to greatest extent, although drysand moulds are preferred where large or intricate work is involved. Low squeeze pressures, 20 to $30 \mathrm{psi}$, are used in machine moulding, since high mould hardness is not required.

\subsection{Moulding Sands}

Both natural and synthetic sands are employed in green-sand moulding for aluminium alloy castings. Whether natural or synthetic sand is used, good sand conditioning is required. Reaction of the molten metal with excess moisture in the sand may result in reaction porosity. 


\subsection{Gating and Risering of Aluminium}

Proper gating and risering of aluminium castings have been recognized as a major factor in producing good castings. To function satisfactorily, good gating and feeding systems must take into account certain wellknown characteristics of aluminium alloys, namely

1. Drossing tendency

2. Gas entrainment

3. Gas absorption

4. Solidification shrinkage (feeding requirements)

5. Difficulty of eliminating macro shrinkage

6. High thermal conductivity

\subsection{Risering}

A riser or a feeder head is a passage of sand made in the cope (mold) during ramming the cope. The primary function of the riser (attached with the mold) is to feed metal to the solidifying casting so that shrinkage cavities are get rid of. Shrinkage is of common defect. Risers promote directional solidification. Riser and directional solidification are interrelated because when solidification proceeds directionally from the casting towards the riser, the result is sound casting.

A riser should perform its function in the most economical manner. Making its small can reduce weight of the riser. Riser size can be reduced by making solidification more directional i.e., by extracting heat more quickly from the casting than from the riser. Riser insulation also, like chilling, promotes directional solidification and increases the yield. Besides riser size, riser location is also important as regards directional solidification.

The proper feeding of aluminum castings involves the solution of two problems:

1. Prevention of macro shrinkage, large visually detectable shrinkage cavities, usually concentrated at hot spots.

2. Prevention of micro shrinkage, shrinkage that can usually be observed only by microscopic examination or Xray or radiographic inspection and which usually is quite widely dispersed. Dissolved gases are particularly harmful if the elimination of micro shrinkage is desired.

\subsection{Dimensions}

a) Casting Dimension

\begin{tabular}{|c|c|c|c|c|c|c|}
\hline Plate casting & \multicolumn{3}{|c|}{ Casting dimensions, $\mathrm{mm}$} & \multirow{2}{*}{$\begin{array}{l}\text { Surface area, } \\
\mathrm{mm}^{2}\end{array}$} & \multirow{2}{*}{$\begin{array}{l}\text { Volume } \\
\mathrm{mm}^{3} \\
\mathrm{X} 10^{4}\end{array}$} & \multirow{2}{*}{$\begin{array}{l}\text { Casting } \\
\text { modulus } \\
\mathrm{mm}\end{array}$} \\
\hline Plate & Length & Width & Thickness & & & \\
\hline & 240 & 150 & 25 & 91500 & 90 & 9.84 \\
\hline
\end{tabular}

Table 2.1 Casting Dimension

\section{b) Riser Dimensions}

Riser-neck dimensions is important because it determines, first, how well the riser can feed the casting, and second, how readily the riser can be removed from the casting. It may also control to some extent the depth of the shrinkage cavity by solidifying just before the riser freezes, thereby preventing the cavity from extending into the casting. Riser-neck dimensions from, for side riser are given below

$\mathrm{H}_{\mathrm{N}}=(0.6$ to 0.8$) \mathrm{t}$

Max. $\mathrm{L}_{\mathrm{N}}=\mathrm{D} / 3$

$\mathrm{W}_{\mathrm{N}}=2.5 \mathrm{~L}_{\mathrm{N}}-0.18 \mathrm{D}$

Where $\mathrm{H}_{\mathrm{N}}=$ Height of the gate, $\mathrm{L}_{\mathrm{N}}=$ Length of the gate, $\mathrm{W}_{\mathrm{N}}=$ width of the gate

$\mathrm{D}=$ diameter of riser, $\mathrm{t}=$ plate thickness.

According to Chvorinov's equation

Solidification time (t) $\alpha$ [Volume / Surface Area 2

It does indicate that, for a riser to have a solidification time equal to or greater than that of the casting, the minimum riser size would be obtained from a sphere. Sphere are usually difficult to mould, and would present feeding problem as well, since the last metal to freeze would be near the center of the sphere, where it could not be used to feed a casting. Practicalities dictate the use of cylinders for most risers. So the cylindrical riser with hemispherical base is used to provide the smallest possible surface area - volume ratio. 

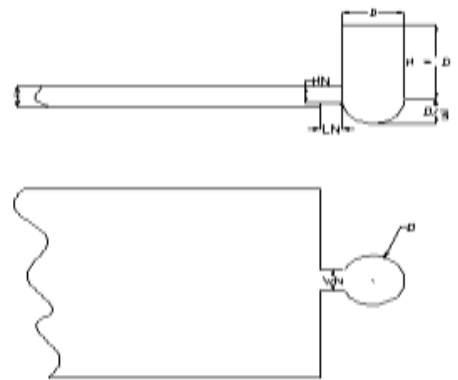

Fig.2.1 Riser Neck Dimensions

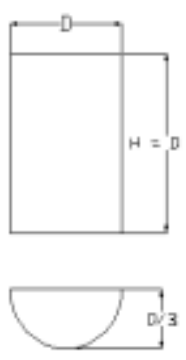

Fig.2.2 Riser with hemispherical bottom

A cylindrical riser with a hemispherical bottom is used in this project since the hemispherical bottom consumes $16-17 \%$ less metal than the standard cylindrical side riser.

\begin{tabular}{|c|c|c|l|l|}
\hline \multicolumn{2}{|c|}{ Riser dimensions, $\mathrm{mm}$} & $\begin{array}{l}\text { Surface } \\
\text { area, } \\
\mathrm{mm}^{2} \mathrm{X} 10^{4}\end{array}$ & $\begin{array}{l}\text { Volume, } \\
\mathrm{mm}^{3} \\
\mathrm{X} 10^{4}\end{array}$ & $\begin{array}{l}\text { Riser } \\
\text { modulus, } \\
\mathrm{mm}\end{array}$ \\
\hline Diameter & Height & 7.789 & 121.16 & 15.55 \\
\hline 105 & 105 & 7.065 & 104.66 & 14.85 \\
\hline 100 & 100 & 6.376 & 89.73 & 14.07 \\
\hline 95 & 95 &
\end{tabular}

Table 2.2 Riser Dimension

\section{COMPUTER SIMULATION}

In the past, the optimal casting design was achieved by trial and error method. With the growing competition in the foundry industry, the conventional approach which is time consuming and ineffective, can no longer satisfies the needs of the foundry. This problem, however, can be minimized with the assistance of computer aided design/engineering technique.

The use of solidification model, which is basically a mathematical analysis tool implemented on computer to simulate the solidification phenomena, for casting design have gradually become popular in recent years. With the help of the computer a number of CAD/CAM commercial packages for the simulations of the casting have been developed and implemented in the foundry.

In this project work, ANSYS 10.0 software has been used to find the optimum dimensions of the riser for rectangular plate Al-alloy castings with cast iron end-chill. Solidification simulation process facilitates to visualize the temperature distribution in various locations of the casting. Cooling curve obtained from simulation helps to find out the solidification time of casting and riser.

\subsection{Preprocessing}

as follows

The preprocessing process contains the following commands to create a finite element model. They are

1. Defining Element and Options

2. Defining Element Real constants

3. Defining Material Properties

4. Creating Model Geometries

5. Defining Meshing controls

6. Applying Boundary Conditions, loads.

\subsection{Model}

Once the model has been created and subjected to various boundary conditions ANSYS solves the set of equations generated by Finite Element Model.

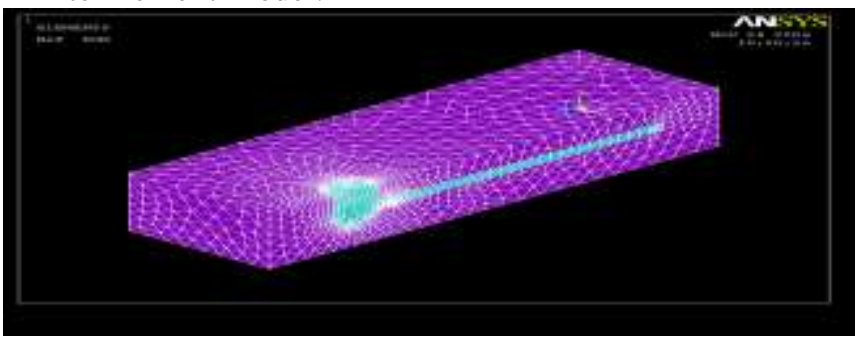

Fig.3.1 Model with Meshing 


\subsection{Solidification Simulation}

The casting and mould assembly is modeled in the preprocessor stage of simulation. One half of the casting and mould assembly is modeled as it is symmetric. The convection takes place all surfaces of sand except bottom surface. The mould is assumed to be instantaneously filled with the molten metal at a pouring temperature of $720^{\circ} \mathrm{C}$.

The mould outside surface is assumed to be convection with film coefficient is $35^{\circ} \mathrm{C}$ because moisture in the sand will affect the cast metal. So, the sand is preheated up to $35^{\circ} \mathrm{C}$. And all relevant data such as material properties, geometry and boundary conditions are entered into the database in preparation for solution.

a. Mould material: Silica sand
Density
: $1580 \times 10-9 \mathrm{~kg} / \mathrm{mm} 3$
Thermal conductivity
Specific heat$$
\text { : } 0.393 \times 10-3 \mathrm{~W} / \mathrm{mm}^{\circ} \mathrm{C}
$$$$
\text { : } 1046 \mathrm{~J} / \mathrm{kg}^{\circ} \mathrm{C}
$$

b. Cast metal : LM6 (Al-12\%Si) Alloy

\begin{tabular}{|l|l|l|l|l|}
\hline $\begin{array}{l}\text { Temperature } \\
{ }^{\circ} \mathrm{C}\end{array}$ & $\begin{array}{l}\text { Density }(\rho) \\
\mathrm{Kg} / \mathrm{mm} 3\end{array}$ & $\begin{array}{l}\text { Specific heat }(\mathrm{Cp}) \\
\mathrm{J} / \mathrm{K}^{\circ} \mathrm{C}\end{array}$ & $\begin{array}{l}\text { Thermal } \\
\text { conductivity }(\mathrm{K}) \\
\mathrm{W} / \mathrm{mm}^{\circ} \mathrm{C}\end{array}$ & $\begin{array}{l}\text { Enthalpy } \\
\mathrm{J} / \mathrm{Kg}\end{array}$ \\
\hline 500 & $2707 \times 10-9$ & 1050 & 0.143 & $20 \mathrm{e} 7$ \\
\hline 600 & $2657 \times 10-9$ & 1050 & 0.143 & $300 \mathrm{e} 7$ \\
\hline 660 & $2385 \times 10-9$ & 1050 & 0.280 & $600 \mathrm{e} 7$ \\
\hline
\end{tabular}

Table 3.1 Cast Metal Properties

c. Initial Conditions :

Casting temperature: $720^{\circ} \mathrm{C}$

Mould temperature : $\quad 35^{\circ} \mathrm{C}$

d. Boundary Conditions :

Sand side surface convection : $4.09 \mathrm{~W} / \mathrm{m} 2{ }^{\circ} \mathrm{K}$

Sand top surface convection : $3.48 \mathrm{~W} / \mathrm{m} 2{ }^{\circ} \mathrm{K}$

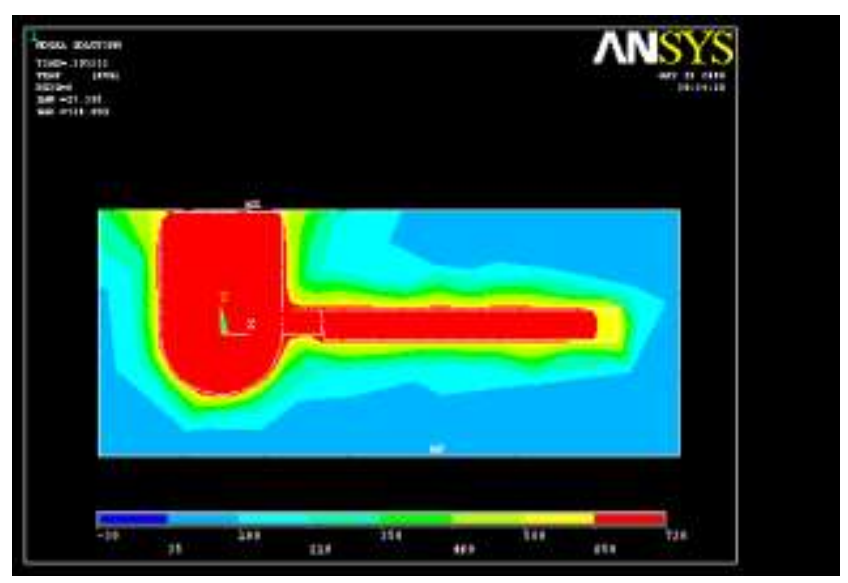

Fig.3.2 Distribution of Temperature after $60 \mathrm{sec}$

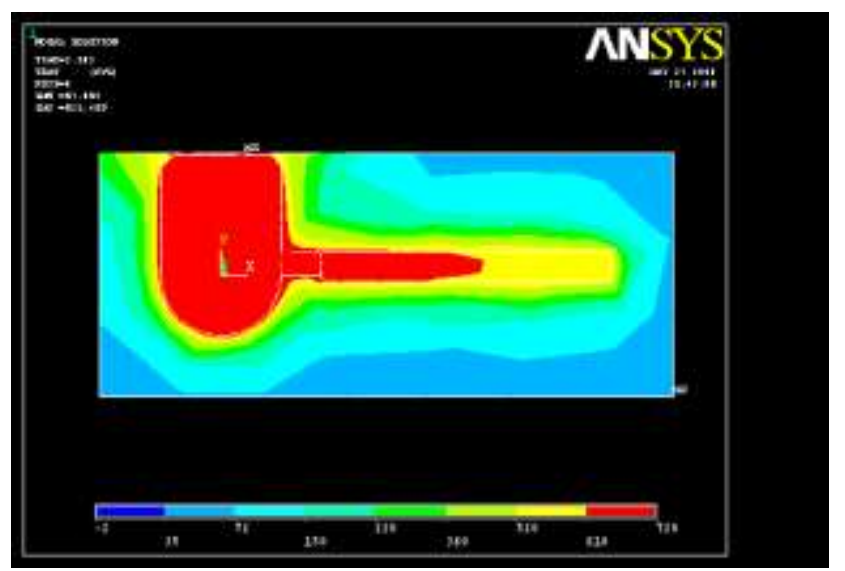

Fig.3.3 Distribution of Temperature after $105 \mathrm{sec}$ 


\subsection{Results Obtained in Computer Simulation}

\begin{tabular}{|c|c|c|c|}
\hline Riser diameter (mm) & $\begin{array}{c}\text { Solidification time in } \\
\text { ANSYS }(\mathrm{sec})\end{array}$ & $\begin{array}{c}\text { FR } \\
(\mathrm{Mr} / \mathrm{Mc})\end{array}$ & $\begin{array}{c}\text { VR } \\
(\mathrm{Vr} / \mathrm{Vc})\end{array}$ \\
\hline 105 & 192 & 1.58 & 1.346 \\
\hline 100 & 178 & 1.505 & 1.162 \\
\hline 95 & 170 & 1.429 & 0.997 \\
\hline
\end{tabular}

Table 3.2 Computer Simulation Result

Where,

$\mathrm{V}_{\mathrm{c}}$ - Volume of casting

$\mathrm{V}_{\mathrm{r}}$ - Volume of Riser

$\mathrm{F}_{\mathrm{R}}$ - Freezing ratio $=$ (modulus of riser/ modulus of casting)

$\mathrm{V}_{\mathrm{R}}$ - Volume ratio $=($ volume of riser / volume of casting $)$

From the caine's curve those points that fall above the curve are said to form sound casting while those that fall below the curve prove to be unsound casting. In this riser size 105 and $100 \mathrm{~mm}$ are sound casting.

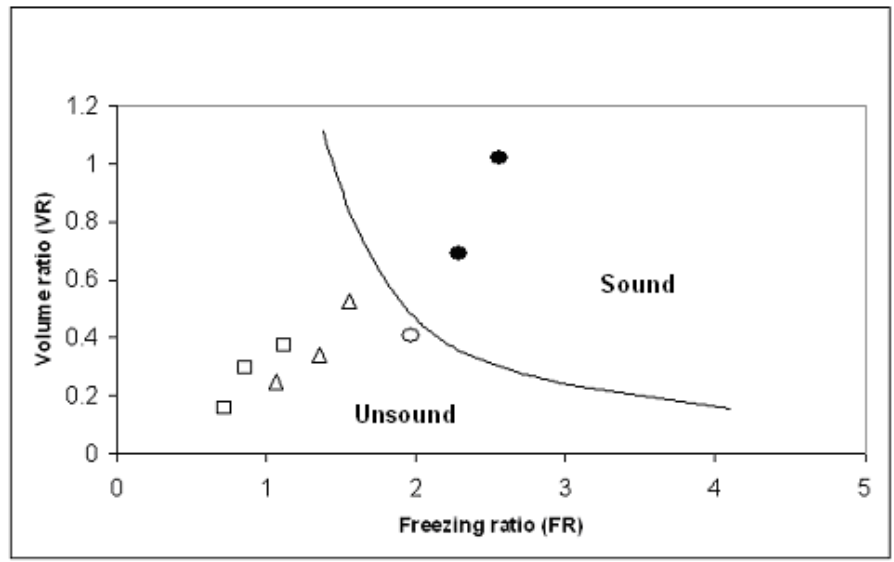

Fig 3.4Caine Analysis

\section{EXPERIMENTAL PROCEDURE}

\subsection{Moulding Sand}

Silica sand moulds are prepared using sand mix with a composition of $8 \%$ calcium based bentonite, $5 \%$ moisture (approx.) and 2\% saw dust and coal powder are added.

\subsection{Melting and Pouring}

The LM6 Aluminium alloys are melted in a crucible furnace. As soon as the molten metal reaches a temperature of $740^{\circ} \mathrm{C}$, it is taken out and degassed using the required quantity of degassing tablets of ALDEGAS (Hexa chloro ethane) in order to remove the dissolved hydrogen gas. Aluminium alloys will absorb or dissolve harmful quantities of hydrogen from atmosphere during melting and pouring.

If the molten metal reaches the pouring temperature $\left(720^{\circ} \mathrm{C}\right)$, subsequent cooling and solidification will result in gas evolution, pinholes, and microscopic gas porosity. So degassing is performed to minimize these defects. The presence of oxides and coal ash in the surface of the molten metal are skimmed. Then the molten metal is poured into the mould cavity at a temperature of $720^{\circ} \mathrm{C}$.

\subsection{Casting Experimental Setup}

Rectangular plate casting size of $240 \times 150 \times 25 \mathrm{~mm}$ is selected as test casting for the investigation. The wooden pattern for the test casting and runner and cylindrical riser with hemispherical bottom of H/D ratio $=1$ are made. For the experimental work about $15.5 \mathrm{Kg}$ of Aluminium has been collected and are cut into small billets using power hacksaw. 

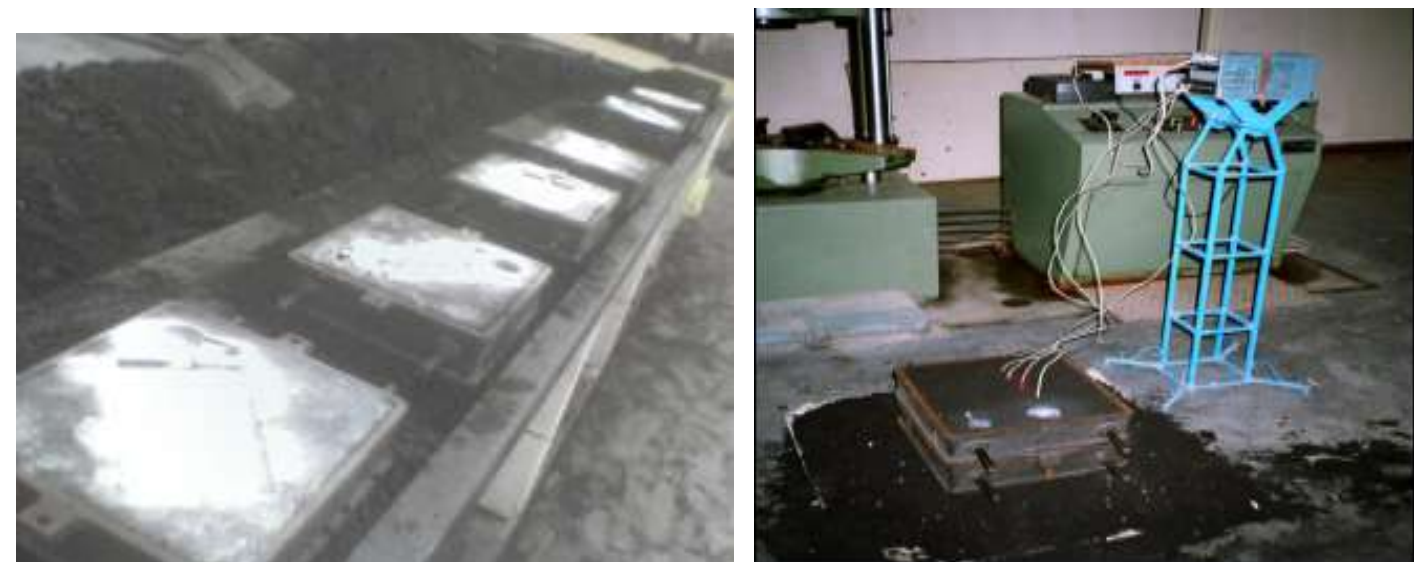

Fig. 4.1 Moulds

Fig.4.2 Experimental Setup with Eurotherm meter

Thermocouples are temperature sensors used to record the temperature distribution at specific points in the casting. Aluminium-Chromium flat wire thermocouple capable of measuring Temperatures up to 900o c has been used. In this experiment cooling curves are taken at four points namely from, Riser end, 60mm from riser end, $100 \mathrm{~mm}$ from riser end, $180 \mathrm{~mm}$ from riser end. The thermocouples are connected to Eurotherm meter which records the casting solidification in form of cooling curves. The castings are produced and are marked to cut specimens. The specimens are employed with tests like density test and ultimate tensile strength test to view their soundness.

\subsection{Measurement of Soundness}

Casting soundness is assessed by measurement of UTS and percentage of porosity. Porosity and mechanical properties of the castings are determined by taking test specimens along the length of the casting.

\section{a. Density Measurement}

The density of the test blanks marked "D" in Fig.6.6 is determined by using Archimedes principle, Archimedes Principle:

Where,

$\rho_{\mathrm{m}}-$ Density of casting $\left(\mathrm{gm} / \mathrm{cm}^{3}\right)$

$\rho_{\mathrm{w}}-$ Density of water $\left(\mathrm{gm} / \mathrm{cm}^{3}\right)$

$\mathrm{W}_{\mathrm{m}-\mathrm{a}}-$ Weight of casting in air (gram)

$\mathrm{W}_{\mathrm{m}-\mathrm{w}}-$ Weight of casting in water (gram)

$$
\rho_{\mathrm{m}}=\left[\frac{\mathrm{W}_{\mathrm{m}-\mathrm{a}}}{\mathrm{W}_{\mathrm{m}-\mathrm{a}}-\mathrm{W}_{\mathrm{m}-\mathrm{w}}}\right] \times \rho_{\mathrm{w}}
$$

The weight of the metal in air and water is measured with help of physical balance.

\section{b. Porosity Measurement}

The porosity percentage of the specimen is calculated by using the maximum density for the alloy and the measured density as shown below.

$$
\begin{aligned}
& \mathrm{P}=\left[\frac{\mathrm{D}_{\mathrm{MAX}}-\mathrm{D}}{\mathrm{D}}\right] \times 100 \% \\
& \text { Where, } \mathrm{P}=\text { Porosity } \\
& \mathrm{D}_{\mathrm{MAX}}-\text { Maximum Density (Theoretical Value). } \\
& \mathrm{D}-\text { Measured Density (Experimental Value). }
\end{aligned}
$$

\section{c. Tensile test specimen}

In order to conduct the tensile test, the plate casting is cut into small pieces and then machined to tensile test specimen.

\section{d. Test Casting}

Test casting with equal modulus riser (i.e. casting modulus equal to riser modulus) is made as shown in figure. Then the tensile test specimen is machined from the test casting. The porosity, ultimate tensile strength are determined experimentally. Number of specimen pieces are cut from the plate casting, and then machined to standard tensile test specimen. The minimum ultimate tensile strength and the maximum porosity of each piece are determined in order to decide whether the casting is sound and unsound. 


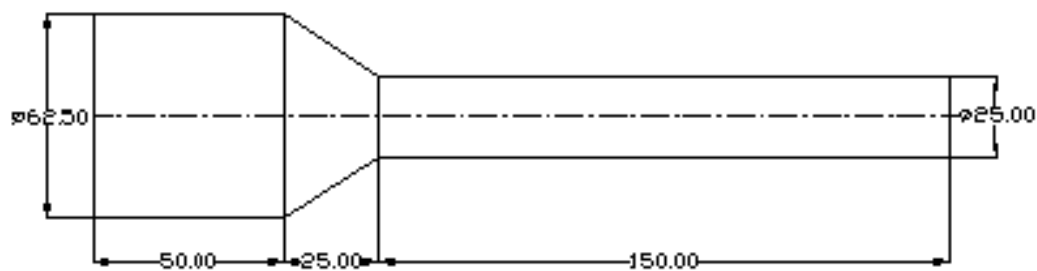

ALL DJMENSJONS ARE JN MMN

Fig. 4.3 Dimensions of the test Casting

\subsection{Results Obtained in Experimental}

\begin{tabular}{|c|c|c|c|c|}
\hline S.NO & Riser diameter $(\mathrm{mm})$ & $\mathrm{D}_{\text {act }}(\mathrm{gm} / \mathrm{cc})$ & Porosity $(\%)$ & UTS $\left(\mathrm{kg} / \mathrm{mm}^{2}\right)$ \\
\hline 1 & 105 & 2.6143 & 1.345 & 11.5 \\
\hline 2 & 100 & 2.6026 & 1.787 & 11.2 \\
\hline 3 & 95 & 2.5969 & 2.005 & 11.1 \\
\hline
\end{tabular}

Table 4.1 Experimental Result

\section{CONCLUSION}

The optimum riser dimensions for a rectangular double plate casting of size $240 \times 150 \times 25 \mathrm{~mm}$ with riser height $\mathrm{H} / \mathrm{D}$ ratio=1 are determined by computer simulation using ANSYS software. The optimum riser diameter of $100 \mathrm{~mm}$ was found. The simulation results are verified experimentally for the optimal riser size and for the soundness of the casting. The plate casting properties such as porosity and ultimate tensile strength are compared with test casting properties and it is observed that the riser diameter computed by ANSYS software is optimum and produces sound casting.

From the experimental results obtained it is confirmed that the diameter of riser $100 \mathrm{~mm}$ and also has promoted the directional solidification which adds up to the casting soundness. While comparing ANSYS result with the experimental results it is found that the observations were found to be very nearest.

\section{REFERENCES}

[1] E. N. PAN, C. S. LIN, and C.R. LOPPER, 1990, "Effects of solidification parameters on the feeding efficiency of A356 Aluminium alloy", AFS Transactions, Vol.98, p.135 -146.

[2] R.C.WILLMS, 1985, "Use of Insulating Material to Extend Feeding Distances for Steel Castings", AFS Transactions, Vol.93, p. $167-170$.

[3] KUN-DAR LI and EDWARD CHANG, 2003, "Explanation of the Porosity Distribution in A206 Aluminium Alloy Castings", AFS Transactions, Vol.111, p.267 - 273 .

[4] J.H. KUO, P. J. CHENG, and W.S. HWANG, 2001, "Measurement of Density of A356.2 Aluminium alloy from $25^{\circ} \mathrm{C}$ to $750^{\circ} \mathrm{C}$ by modified Archimedes Method", ATS Transactions, Vol.109, p.461 - 468.

[5] ROBERT C. CREESE, 1983, "The Potential Metal Savings in Cylindrical Top Risers with Insulating Materials" AFS Transactions, Vol. 91, p.447 - 450 .

[6] R.A. JOHNS, 1980, "Risering Steel Castings easily and Efficiently", AFS Transactions, Vol.88, p.77 - 96

[7] R.C. CREESE, 1981,"Cylindrical Top Riser Designs Relationship for Evaluating Insulating Materials", AFS Transactions, Vol. 89, p. $354-348$

[8] R.C. CREESE, 1979, “An Evaluation of Cylinder Riser Designs with Insulating Materials”, AFS Transactions, Vol. 87, p. 665 668.

[9] M.S. RAMA PRASAD, M.N. SRINIVASAN, and M.R. SESHADRI, 1978, "Using Insulating Materials for Feeders heads in Nonferrous Castings", AFS Transactions, Vol. 86, p. $431-438$. 